\title{
GLASS IONOMER CEMENTS AND THEIR ROLE IN THE RESTORATION OF NON-CARIOUS CERVICAL LESIONS
}

\author{
Luciana Fávaro FRANCISCONI ${ }^{1}$, Polliana Mendes Candia SCAFFA ${ }^{2}$, Vivian Rosa dos Santos Paes de BARROS ${ }^{3}$, \\ Margareth COUTINHO ${ }^{4}$, Paulo Afonso Silveira FRANCISCONI ${ }^{5}$
}

\author{
1- DDS, MSc, PhD Student, Department of Operative Dentistry, Endodontics and Dental Materials, Bauru School of Dentistry, University of São Paulo, \\ Bauru, SP, Brazil. \\ 2- DDS, MSc, PhD Student, Department of Restorative Dentistry, Dental Materials Area, Piracicaba School of Dentistry, University of Campinas, \\ Piracicaba, SP, Brazil \\ 3- DDS, MSc Student, "Doutor Hélio Mandetta" School of Medicine, Federal University Foundation of Mato Grosso do Sul, Campo Grande, MS, \\ Brazil. \\ 4- DDS, PhD, Associate Professor, "Doutor Hélio Mandetta" School of Medicine, Federal University Foundation of Mato Grosso do Sul, Campo \\ Grande, MS, Brazil. \\ 5- DDS, PhD, Associate Professor, Department of Operative Dentistry, Endodontics and Dental Materials, Bauru School of Dentistry, University of São \\ Paulo, Bauru, SP, Brazil. \\ Corresponding address: Luciana Fávaro Franciscon - Departamento de Dentística, Endodontia e Materiais Dentários, FOB/USP - Alameda Dr. Octávio \\ Pinheiro Brisolla, 9-75 - Cx Postal 73 - 17012-901 - Bauru, SP, Brasil - Phone: +55 1432358263 - Fax: +55 1432261495 - e-mail: luff@usp.br \\ Received: June 11, 2008 - Modification: August 31, 2008 - Accepted: November 9, 2008
}

\begin{abstract}
G

lass ionomer based materials are clinically popular in several areas of restorative dentistry, but restoration of cervical lesions has proven particularly successful. Various etiologies, conformations, locations and structural characteristics make non-carious cervical lesions more challenging to adhesive restorative procedures and marginal seal in the long run. Due to their characteristics, glass ionomer cements (GICs) have precise indication for these cases. Moreover, the use of a GIC base underneath composite resin, the so-called "sandwich" or mixed technique, allows associating the good characteristics of composite resins and GICs, and has been considered quite useful in the restoration of non-carious cervical defects. The aim of this paper is to critically review the literature and discuss peculiar features of GICs regarding their role in the restoration of non-carious cervical lesions.
\end{abstract}

Key words: Glass ionomer cements. Tooth erosion. Tooth abrasion. Dental restoration, permanent.

\section{INTRODUCTION}

Non-carious cervical lesions are a challenging dental problem that requires professional attention. Their prevalence has increased due to the implementation of preventive dentistry and caries control, and patient complaints have started to be more and more related to this kind of lesions ${ }^{1,14,59}$. The incidence of non-carious cervical lesions increases with age and are associated with middleaged patients. Composite resin and glass ionomer cements (GICs) have been indicated as the restorative materials of choice for these cases ${ }^{34,37}$. GICs, however, have a wider range of clinical applications in non-carious cervical lesions ${ }^{38}$. These materials are capable to form satisfactory bonds with enamel and dentin, release fluoride over a prolonged period, promote good biological response (biocompatibility) $)^{21,32}$ and have a coefficient of thermal expansion close to that of tooth structures $^{34}$. The aim of this paper is to critically review the literature and discuss peculiar features of GICs regarding their role in the restoration of non-carious cervical lesions.

\section{GICs}

Wilson and Kent ${ }^{57}$ (1970) were trying to overcome shortcomings of silicate cements and to retain or improve their advantages when they developed GIC. This material was developed by combining strength, rigidity, and fluoride release properties of a silicate glass powder with the biocompatibility and adhesive characteristics of a polyacrylic acid liquid. This turned out to be a hybrid cement of silicate/polycarboxylate consisting of calcium fluoroaluminosilicate glass powder and polyacrylic and itaconic acid liquid. When first developed, the GIC was labeled ASPA for its basic ingredients: "A"lumino "S"ilicate powder and "P"olyacrylic-"A"cid liquid" .

From the first development of GIC, it was understood that the acid-base reaction involved in the setting mechanism for these materials was hydrolytically unstable in its early stages. This meant that they were very sensitive to water loss and water uptake for at least one hour after mixing ${ }^{21,56}$, during which it is possible for the cement to dehydrate if left exposed to air. Alternatively, if the materials are exposed 
to water, there will be considerable water uptake and elution of essential ions. It was shown later, that the period of sensitivity for the restorative esthetic materials is even longer, and it is convenient to maintain them in isolation for up to $24 \mathrm{~h}^{21,29,56}$.

In addition to these disadvantages, there are a number of advantages in the use of GICs, especially for restorations that are not under heavy occlusal load. The ion exchange adhesion with tooth structure is unique, and the strength is yet to be measured ${ }^{4}$. Bond failures reported up to now have represented cohesive failure in the cement rather than adhesive failure at the interface with tooth structure ${ }^{23}$. Fluoride released from GICs to the surrounding tissues provides secondary caries inhibition ${ }^{5,8,23,36}$, and abrasion resistance is very high once it has matured in the oral environment. Clinical performance, concerning color match, marginal discoloration, marginal adaptation and anatomical form, satisfactorily resemble that of composite resin cervical restorations and, in fact, GIC restorations seem to be superior, in terms of retention rates $\mathrm{s}^{7,12,34,42}$.

Since their development, GICs have suffered changes in both glass powder component and in polycarboxylic acid liquid. Modifications in both components have been made in various brands for both patent and practical reasons. Silver alloy, pigments, or radiopaque materials have been added to the powder, depending on its intended use. One of the most important changes in their composition was the addition of ingredients to allow light-curing ${ }^{21,32}$.

These new materials are, thus, hybrid materials that retain a significant acid/base reaction as part of their overall curing process. They present improved setting characteristics over conventional GIC, sufficiently long working time that can be shortened by photo-curing, and a rapid development of early strength, which in turn, renders the set matrix less intolerant to the effect of moisture ${ }^{32,44,48,58}$. These materials also have a number of less immediate advantages. The translucency of the restorative material is markedly better than conventional GICs, and color matching is less of a "hitand-miss affair", apart from being doubtful in the long run ${ }^{20}$. Repairs to defective or damaged surfaces of resin-modified GICs (RMGICs) are easily carried out, and there is an apparent improvement in adhesion to suitable prepared dentine surfaces ${ }^{32}$. Also, these materials can bond directly to composite resin and thus are well indicated for the "sandwich" technique", which got its name from the fact that, in this particular usage, GICs are "sandwiched" between the underneath tooth surface and the other restorative material above, which is usually composite $\operatorname{resin}^{4,40}$.

\section{GICs APPLICATIONS}

GIC-based materials are clinically popular in several different areas of restorative dentistry - as linings underneath other restorative materials, as luting agents, as well as for core build-up, and for restorations $\mathrm{s}^{50}$. For each of these clinical uses, numerous justifications are available. GICs have very low shrinkage and are thermally compatible with tooth structure. They can even bond to dentin surfaces without the removal of the smear layer and their biologic compatibility is well proved. For these reasons, they can be effectively used as lining materials ${ }^{27}$.

The use of GICs as luting agents has also been reported to having great success. They are used to cement stainless steel crowns for primary teeth, precision cast crowns and fixed prostheses for permanent teeth, space maintainers, and single orthodontic bands. High-caries-risk patients are particularly benefited with the use a luting cement that has leachable fluoride ions and associate preventive dentistry implications ${ }^{31}$.

GICs are also very suitable for core build-ups. They are used to repair tooth structure defects prior to crown preparation and stabilize weakened portions of the tooth. The objective of this procedure is to achieve the most reliable possible retention of the crown. Ideally, the core build-up material should form a durable connection with the tooth stump and show dentin-like properties regarding hardness and grindability. Today, amalgam, GICs, or composites are normally used as core build-up materials. GICs, however, have been the preferred core build-up materials for a long time because of their chemical adhesion to the tooth structure $^{47}$.

As a restorative material, GIC bond to the enamel and dentin via ionic and polar bonds, and the intimate molecular contact facilitates ion exchange of fluoride with the hydroxyl ions in the apatite of the surrounding enamel ${ }^{5,39}$. These features are especially interesting when the material is used as fissure sealant, or for preventive and cervical restorations. The use of GICs to restore cervical lesions proved especially successful ${ }^{25}$.

\section{NON-CARIOUS CERVICAL LESIONS AND THE ROLE OF GICs}

Nowadays, due to preventive dentistry (intense caries control) and modifications in humans' diet, non-carious cervical lesions started to be commonly observed, mostly in developed countries $\mathrm{s}^{3,6,30,33}$. These lesions of multifactorial tooth wear, can be attributed to the action of chemical agents (dental erosion), physical agents (abrasion), or even to alterations in force distribution on the tooth (abfraction). It is also important to consider root exposure of teeth, when it is present for long periods, as this could contribute to noncarious cervical lesions formation. Normally, more than one of these factors act simultaneously and the lesions acquire unique characteristics that result in very complex differential diagnoses and a challenging restorative treatment ${ }^{22,59}$.

The treatment of non-carious cervical lesions can usually start with the control of the etiologic factor, following an evaluation of dentin sensitivity. Desensitizing techniques are based on the application of copal varnishes, potassium oxalate and other desensitizing materials. However, they provide only a palliative pain treatment. When the former procedures are not effective, other factors such as food accumulation prevention, dentin-pulp complex protection, aesthetics improvement, erosion and dentifrice abrasion protection, and control of dentinal sensitivity should be considered as indications for the restoration of non-carious cervical lesions. In this context, light-cured GIC could be 
used with certain advantages ${ }^{2}$. According to Santiago, et al. ${ }^{42}$ (2003), special characteristics of these lesions are the presence of dentin or cementum in the gingival margins, and restorations that are more susceptible to microleakage and postoperative sensitivity because the available dentin is not favorable to adhesive systems, due to its higher mineral concentration (hypermineralized dentin). Along with lack of mechanical retention and difficulty to control moisture contamination in doing these restorations, the longevity and marginal sealing are challenged.

GICs are very durable in cervical restorations and compete with the composites, particularly where bonding to cervical dentin is required. Sclerosed dentin remains the greatest obstacle to obtain good bonding with dentinal bonding agents, and failure at the cervical margin, as a result of microleakage, is not always easily detected ${ }^{26}$. Dijken ${ }^{55}$ (2005), for example, showed that removal of the outer surface layer of the sclerotic dentin by roughening with a diamond bur did not improve retention for RMGICs, as shown in earlier published studies ${ }^{52,53}$.

Taking these aspects into account, it is important to consider that, although measurements of in vitro bond strengths reveal lower values for GIC compared to resinbased adhesive systems, evaluations in non-carious cervical lesions restored with GICs showed good long-term retention $^{54,55}$. High retention rates were recorded by Gladys, et al. ${ }^{15}$ (1998) after 18 months: no cervical restorations were lost for Fuji II LC and Vitremer. Therefore, GICs maintain the adhesion for long periods and are the materials of choice to be used in the cervical area of teeth where no cavity preparation is contemplated. It is also important to consider that adhesion to dentin is enhanced by surface conditioning with a $25 \%$ solution of polyacrylic acid for $10 \mathrm{~s}^{39}$.

For these reasons, questioning on the right choice will depend on esthetic demands and on the maintenance of polished surfaces. Modern composites restorations have great esthetic appeal, but both conventional GICs and RMGICs have been considerably improved with regard to translucency and color. Although composite restorations may exhibit esthetics in the first years, standard GICs can have greater color stability because of their chemical stability ${ }^{24}$.

As seen above, non-carious cervical lesions can present great structural loss in enamel margins, especially in regions close to the gingiva, and so beveled enamel margins, which are necessary for composite restorations to enhance adhesive procedures, are contraindicated in order to preserve the remaining structure. The defective regions could be then restored with GICs since beveled margins are not recommended for these materials due to their fragility when placed in insufficient volume in the cavity. GICs are especially effective for the treatment of non-carious cervical lesions, bonding chemically to the calcium of the tooth structure, and avoiding unnecessary removal of enamel for cavity margin beveling. Also, the compatibility between thermal expansion coefficients from the tooth structure and from GICs makes mechanical retentions unnecessary, wich saves remaining tooth structure ${ }^{46}$. The retention of GIC, in these situations, is up to 90 and $100 \%$ after 3 years of observation $^{22}$.

$\mathrm{Sidhu}^{43}$ (1994), evaluated the presence of toothrestoration interfacial failures in the seal of cervical cavities with margins in dentin restored with conventional and resinmodified GICs. After thermocycling, the conventional GIC presented interfacial gaps measuring $26 \mu \mathrm{m}$ on average while the RMGICs presented interfacial gaps measuring 8 to 10 $\mu \mathrm{m}$ on average. The light cured materials showed a better adaptation to the cavity walls when compared to chemical setting GIC, though without statistical significance.

According to Tyas, ${ }^{51}$ (1995) modifications in the conventional formulations of GICs and restorative techniques increased remarkably the clinical success of class $\mathrm{V}$ restorations. Advantages such as improved bond strength, better physical proprieties, better polishing, wider color range and translucence were obtained with the advent of dual-cured cements, for example. In addition to having a simplified technique, these materials present an excellent long-term performance and offer fluoride release, even though they still have surface porosity as a possible disadvantage. RMGICs have good retention results, reduced superficial degradation and increased wear resistance when compared to conventional GICs. In addition to this, according to the author, the use of conditioners and primers containing HEMA prior to the application of GICs promotes an adhesion very similar to the hybrid layer, observed with the use of adhesive bond systems and associated with composite resins.

After the initial setting, according to Pascotto and Navarro $^{35}$ (2004), these cements allow the passage of the pulpal fluid through an absorption layer, formed near the dentinal tubules. This layer can compensate for the polymerization shrinkage of the resin agent, maintaining the marginal seal of the restoration. Moreover, the polymerization stresses developed by GICs are much lower than the ones produced by composite resin, due to their slow setting reaction and smaller resin content in the material. The capacity of GIC to adhere chemically to the tooth structure, allied with their coefficient of thermal expansion similar to that of tooth structures, contribute to better quality and to longevity of restorations, especially in enamel missing margins, common in non-carious cervical lesions ${ }^{35}$.

According to Hanaoka, et al. ${ }^{16}$ (1998), restorative materials used at the cervical region of teeth are frequently subjected to resultants of occlusal loads, and, thus, should present biomechanical features capable of resisting under tension, which is a peculiar feature of GICs. An important aspect to be considered, when selecting a restorative material for NCCL, is the material's capacity to partially absorb the tension generated during loading distribution through the teeth $^{17,60}$.

Although the use of GIC in the rehabilitation of noncarious cervical lesions has remarkable advantages, GIC cervical restorations can be abraded, especially by toothbrushing with dentifrice ${ }^{45}$. Frazier, et al. ${ }^{13}$ (1998) observed that all but one hybrid resin-based ionomer type material exhibited a resistance to toothbrush wear, which was as good as or even better than that of the two traditional 
resin-based evaluated materials. Similar results were obtained by Franco, et al. ${ }^{12}$ (2006) when, after a 5 year evaluation, the clinical performance of RMGIC restorations was superior to that of composite resin restorations. On the other hand, Bracket, et al. ${ }^{7}$ (2002) have shown that although the incidence of failed composite resin restorations was higher than that of GIC restorations, no significant difference was observed in the overall clinical performance between the two materials. Also, Momoi, et al. ${ }^{28}$ (1997) reported that the abrasion resistance of RMGICs was statistically lower for amalgam and for composite resin reference materials. The in vitro resistance of RMGICs to toothbrush/dentifrice abrasion was lower than that of conventional acid-base GICs, and seems to be related to their lower surface hardness.

The other possible mechanism on the development of non-carious cervical lesions is abfraction. The numerical results presented by Ichim, et al. ${ }^{19}$ (2007) clearly show that, under the action of parafunctional loads, fracture and dislodgment induced failure of cervical GIC restorations at the cervical margin. It also shows that prior to fracture the restorative material undergoes strain softening, which in turn introduces damage and weakens the materials involved. Material softening occurs in the cervical region of the restoration, which is associated with the location of most clinical failures. This is in agreement with various clinical studies that have dealt with the longevity and failure of such restorations ${ }^{7,18}$. However, there is limited data about the failure types and little attention has been focused on the biomechanics underlying their failure.

Although this lack of knowledge, in a previous study ${ }^{41}$, both conventional and resin modified GICs subjected to demineralization by the erosive effect of a carbonated drink $\left(\right.$ Coca-cola $\left.{ }^{\circledR}\right)$, showed a passive role towards erosion. They were not capable of minimizing erosive harmful effects on the dental structure ${ }^{41}$, as previously assumed ${ }^{22}$. Still, when used on a short-term basis (7 days), the soft drink caused in situ a loss in the conventional GIC hardness ${ }^{10}$. Both conventional and resin modified GICs showed, in vitro, the highest microhardness losses when compared to other materials and to the control group, stored in saliva ${ }^{11}$. These results could be explained by the matrix dissolution that occurs in the periphery of the glass particles of GICs and could be the result of dissolution of the siliceous hydrogel layer ${ }^{49}$

Some laboratory studies have shown that the sandwich technique could be advantageous if compared to the composite or GIC restorations alone, especially when the gingival margins of the restorations are examined ${ }^{9,21}$. A possible explanation for this is that the base transmits flexure forces to the whole restoration. Another theory states that GIC could be recommended in that there is high amount of calcium ions available in this sclerotic dentin. Furthermore, the replacement of dentin and enamel by GIC and composite resin, respectively lowers the composite polymerization shrinkage, allows the release of fluoride ions and makes it possible to achieve a more polished surface of the restoration. The possible disadvantages of this restorative approach include the increase of time, the complexity and the precision required to place these materials ${ }^{51}$. Therefore, the use of the mixed or sandwich technique to restore deep cervical lesion with no enamel in the cervical margins and no esthetic needs is recommended. Using this approach, the good properties of GICs (adhesion, fluoride release, biocompatibility and thermal expansion coefficient similar to that of the tooth structure) could be associated with those of the composite resins (mechanical resistance, superficial smoothness, esthetics and great color stability) ${ }^{35}$.

\section{CONCLUSIONS}

Along with the development of new dental restorative materials, there has been a better understanding of noncarious lesions and their management, and a thorough discussion in the literature. Based on large scientific evidence, restoration of non-carious cervical lesions with GICs has been summarized, discussed, and proved extremely successful. GICs have very low polymerization shrinkage and are thermally compatible with tooth structure. These materials can bond to dentin surfaces without removing the smear layer and their biological compatibility is well proved. They maintain adhesion for long periods and are the material of choice to be placed in the cervical area of the teeth. In conclusion, it must be emphasized that all patients with tooth wear should periodically return to their dentists even if the lesions had been restored with effective materials, not only to evaluate the lesions, but also to maintain restorations in a good shape and prevent future dental tissue loss.

\section{REFERENCES}

1- Al-Dlaigan YH, Shaw L, Smith A. Dental erosion in a group of British 14-year-old, school children. Part I: prevalence and influence of differing socioeconomic backgrounds. Br Dent J. 2001;190(3):145-9.

2- Azzopardi A, Bartlett DW, Watson TF, Sherriff M. The measurement and prevention of erosion and abrasion. J Dent. 2001;29(6):395-400.

3- Bartlett DW, Phillips K, Smith B. A difference in perspective-the North American and European interpretations of tooth wear. Int $\mathbf{J}$ Prosthodont. 1999;12(5):401-8.

4- Berg JH. Glass ionomer cements. Pediatr Dent. 2002;24(5):430-8.

5- Billington RW, Pearson GJ, Williams JA. Uptake of fluoride ions by the glass component of glass ionomer cement. J Dent. 2007;35(5):452-5.

6- Borcic J, Anic I, Urek MM, Ferreri S. The prevalence of non-carious cervical lesions in permanent dentition. J Oral Rehabil. 2004;31(2):11723 .

7- Brackett MG, Dib A, Brackett WW, Estrada BE, Reyes AA. One-year clinical performance of a resin-modified glass-ionomer and a resin composite restorative material in unprepared class $\mathrm{V}$ restorations. Oper Dent. 2002;27(2):112-6

8- Carey CM, Spencer M, Gove RJ, Eichmiller FC. Fluoride release from a resin-modified glass-ionomer cement in a continuous-flow system: effect of pH. J Dent Res. 2003;82(10):829-32.

9- Croll TP. The "sandwich" technique. J Esthet Restor Dent. 2004;16(4):210-2. 
10- Folwaczny M, Loher C, Mehl A, Kunzelmann KH, Hinkel R. Toothcolored filling materials for the restoration of cervical lesions: a 24-month follow-up study. Oper Dent. 2000;25(4):251-8.

11- Francisconi LF, Honório HM, Rios D, Magalhães AC, Machado MAM, Buzalaf MAR. Effect of erosive $\mathrm{pH}$ cycling on different restorative materials and on enamel restored with these materials. Oper Dent. 2008;33(2):203-8.

12- Franco EB, Benetti AR, Ishikiriama SK, Santiago SL, Lauris JR, Jorge MF, et al. 5-year clinical performance of resin composite versus resin modified glass-ionomer restorative system in non-carious cervical lesions. Oper Dent. 2006;31(4):403-8.

13- Frazier KB, Rueggeberg FA, Mettenburg DJ. Comparison of wearresistance of Class V restorative materials. J Esthet Dent. 1998;10(6):30914

14- Ganss C, Klimek J, Giese K. Dental erosion in children and adolescents-a cross-sectional and longitudinal investigation using study models. Community Dent Oral Epidemiol. 2001;29(4):264-71.

15- Gladys S, Van Meerbeek B, Lambrechts P, Vanherle G. Marginal adaptation and retention of a glass-ionomer, resin-modified glass-ionomers and a polyacid-modified resin composite in cervical Class-V lesions. Dent Mater. 1998;14(4):294-306.

16- Hanaoka K, Nagao D, Mitusi K, Mitsuhashi A, Sugizaki S, Teranaka T. A biomechanical approach to the etiology and treatment of noncarious dental cervical lesions. Bull Kanagawa Dent Coll. 1998;26(2):103-11.

17- Heymann HO, Bayne SC. Current concepts in dentin bonding focusing on dentinal adhesion factors. J Am Dent Assoc. 1993;124(5):2636 .

18- Heymann HO, Sturdevant JR, Bayne S, Wilder AD, Sluder TB, Brunson WD. Examining tooth flexure effects on cervical restorations: a two-year clinical study. J Am Dent Assoc. 1991;122(5):41-7.

19- Ichim I, Li Q, Loughran J, Swain MV, Kieser J. Restoration of noncarious cervical lesions Part I. Modeling of restorative fracture. Dent Mater. 2007;23(12):1553-61.

20- Imparato JC, Garcia A, Bonifácio CC, Scheidt L, Raggio DP, Mendes FM, et al. Color stability of esthetic ion-releasing restorative materials subjected to $\mathrm{pH}$ variations. J Dent Child (Chic). 2007;74(3):189-93.

21- Kovarik RE, Haubenreich JE, Gore D. Glass ionomer cements: a review of composition, chemistry, and biocompatibility as a dental and medical implant material. J Long Term Eff Med Implants. 2005;15(6):655-71.

22- Lambrechts P, Van Meerbeek B, Perdigão J, Gladys S, Braem M, Vanherle G. Restorative therapy for erosive lesions. Eur J Oral Sci. 1996;104(2):229-40.

23- Lucas ME, Arita K, Nishino M. Toughness, bonding and fluoriderelease properties of hydroxyapatite-added glass ionomer cement. Biomaterials. 2003;24(21):3787-94.

24- McLean JW, Wilson AD. The clinical development of the glass-ionomer cement. II. Some clinical applications. Aust Dent J. 1977;22(2):120-7.

25- McLean JW, Wilson AD. The clinical development of the glass-ionomer cement. III. The erosion lesion. Aust Dent J. 1977;22(3):190-5.

26- McLean JW. Dentinal bonding agents versus glass-ionomer cements. Quintessence Int. 1996;27(10):659-67.

27- McLean JW. The clinical use of glass-ionomer cements. Dent Clin North Am. 1992;36(3):693-711.
28- Momoi Y, Hirosaki K, Kohno A, McCabe JF. In vitro toothbrushdentifrice abrasion of resin-modified glass-ionomers. Dent Mater. 1997;13(2):82-8.

29- Mount GJ. Longevity in glass-ionomer restorations: review of a successful technique. Quintessence Int. 1997;28(10):643-50.

30- Negoro T, Briggs J, Plesh O, Nielsen I, McNeill C, Miller AJ. Bruxing patterns in children compared to intercuspal clenching and chewing as assessed with dental models, electromyography, and incisor jaw tracing: preliminary study. ASDC J Dent Child. 1998;65(6):449-548.

31- Nicholson JW, Croll TP. Glass-ionomer cements in restorative dentistry. Quintessence Int. 1997;28(11):705-14.

32- Nicholson JW, Czarnecka B. The biocompatibility of resin-modified glass-ionomer cements for dentistry. Dent Mater. 2008;24(12):1702-8.

33- Oginni O, Olusile AO. The prevalence, aetiology and clinical appearance of tooth wear: the Nigerian experience. Int Dent J. 2002;52(4):268-72

34- Özgünaltay G, Önen A. Three-year clinical evaluation of a resin modified glass-ionomer cement and a composite resin in non-carious class V lesions. J Oral Rehabil. 2002;29(11):1037-41

35- Pascotto RC, Navarro MFL. Aplicações clínicas dos cimentos de ionômero de vidro. In: Gomes JC, editor. Estética em clínica odontológica. Curitiba: Editora Maio; 2004. p. 57-85.

36- Pin ML, Abdo RC, Machado MA, Silva SM, Pavarini A, Marta SN. In vitro evaluation of the cariostatic action of esthetic restorative materials in bovine teeth under severe cariogenic challenge. Oper Dent. 2005;30(3):368-75

37- Powell LV, Gordon GE, Johnson GH. Clinical evaluation of direct esthetic restorations in cervical abrasion/erosion lesions: one-year results. Quintessence Int. 1991;22(9):687-92.

38- Powell LV, Johnson GH, Gordon GE. Factors associated with clinical success of cervical abrasion/erosion restorations. Oper Dent. 1995;20(1):713.

39- Powis DR, Follerås T, Merson SA, Wilson AD. Improved adhesion of a glass-ionomer cement to dentin and enamel. J Dent Res. 1982;61(12):1416-22.

40- Rao V, Reddy VV. An in vitro comparative evaluation of the tensile bond strength at the two interfaces of the sandwich technique. J Indian Soc Pedod Prev Dent. 1995;13(1):10-2.

41- Rios D, Honório HM, Francisconi LF, Magalhães AC, Machado MAM, Buzalaf MAR. In situ effect of an erosive challenge on different restorative materials and on enamel adjacent to these materials. J Dent. 2008;36(2):152-7.

42- Santiago SL, Franco EB, Mendonça JS, Lauris JRP, Navarro MFL. One-year clinical evaluation of tooth-colored materials in non-carious cervical lesion. J Appl Oral Sci. 2003;11(3):175-80.

43- Sidhu SK. Marginal contraction gap formation of light-cured glassionomers. Am J Dent. 1994;7(2):115-8.

44- Smith DC. Development of glass-ionomer cement systems. Biomaterials. 1998;19(6):467-78.

45- Smith WA, Marchan S, Rafeek RN. The prevalence and severity of non-carious cervical lesions in a group of patients attending a university hospital in Trinidad. J Oral Rehabil. 2008;35(2):128-34.

46- Starr S. Class 5 restorations. In: Summit JB, Robbins J, Schwartz R, editors. Fundamentals of operative dentistry: a contemporary approach. Carol Stream: Quintessence; 2001. p. 386-400. 
47- Stober T, Rammelsberg P. The failure rate of adhesively retained composite core build-ups in comparison with metal-added glass-ionomer core build-ups. J Dent. 2005;33(1):27-32.

48- Syrek A. Features of modern GICs and their relevance to clinical practice. J Dent. 2006;34(8):614-22.

49- Turssi CP, Hara AT, Serra MC, Rodrigues AL Jr. Effect of storage media upon the surface micromorphology of resin-based restorative materials. J Oral Rehabil. 2002;29(9):864-71.

50- Tyas MJ, Burrow MF. Adhesive restorative materials: a review. Aust Dent J. 2004;49(3):112-21.

51- Tyas MJ. The Class V lesion: aetiology and restoration. Aus Dent J 1995;40(3):167-70

52- van Dijken JW. Clinical evaluation of three different adhesive systems in Class V non-carious lesions. Dent Mater. 2000;16(4):285-91.

53- van Dijken JW. Durability of three simplified adhesive systems in Class V non-carious cervical dentin lesions. Am J Dent. 2004;17(1):2732 .

54- van Dijken JW. Four-year evaluation of the effect of $10 \%$ polyacrylic acid or water rinsing pretreatment on retention of glass polyalkenoate cement. Eur J Oral Sci. 1996;104(1):64-6.

55- van Dijken JW. Retention of a resin-modified glass-ionomer adhesive in non-carious cervical lesions: a 6-year follow-up. J Dent. 2005;33(7):541-

56- Wilder AD Jr, Swift EJ Jr, , Thompson JY, McDougal RA. Effect of finishing technique on the microleakage and surface texture of resinmodified glass ionomer restorative materials. J Dent. 2000;28(5):367-73.

57- Wilson AD, Kent BE. A new translucent cement for dentistry: the glass-ionomer cement. Br Dent J. 1972;132(4):133-5.

58- Wilson AD. Resin-modified glass-ionomer cements. Int J Prosthodont. 1990;3(5):425-9.

59- Wood I, Jawad Z, Paisley C, Brunton P. Non-carious cervical tooth surface loss: a literature review. J Dent. 2008;36(10):759-66.

60- Yap AU, Neo JC. Non-carious cervical tooth loss. Part 2: Management. Dent Update. 1995;22(9):364-8. 